\title{
Engineering Wood Products from Eucalyptus spp.
}

\author{
Lee Seng Hua $\mathbb{D},{ }^{1}$ Lum Wei Chen $\left(\mathbb{D},{ }^{2}\right.$ Petar Antov $\mathbb{D}^{3}{ }^{3}$ Lubos Kristak $\left(\mathbb{D},{ }^{4}\right.$ \\ and Paridah Md Tahir $\mathbb{D D}^{1}$ \\ ${ }^{1}$ Laboratory of Biopolymer and Derivatives, Institute of Tropical Forestry and Forest Product, Universiti Putra Malaysia, \\ UPM Serdang 43400, Selangor, Malaysia \\ ${ }^{2}$ Institute for Infrastructure Engineering and Sustainable Management, Universiti Teknologi MARA, Shah Alam 40450, \\ Selangor, Malaysia \\ ${ }^{3}$ Faculty of Forest Industry, University of Forestry, Sofia 1797, Bulgaria \\ ${ }^{4}$ Faculty of Wood Sciences and Technology, Technical University in Zvolen, Zvolen 96001, Slovakia
}

Correspondence should be addressed to Lee Seng Hua; lee_seng@upm.edu.my and Lubos Kristak; kristak@tuzvo.sk

Received 10 December 2021; Accepted 15 January 2022; Published 2 February 2022

Academic Editor: Veronica Calado

Copyright $\odot 2022$ Lee Seng Hua et al. This is an open access article distributed under the Creative Commons Attribution License, which permits unrestricted use, distribution, and reproduction in any medium, provided the original work is properly cited.

Forest covers 4.06 billion hectares (ha) or $31 \%$ of the total land area worldwide, where $93 \%$ (3.75 billion ha) are natural regenerating forests and the remaining 7\% (294 million ha) are planted forests. Eucalyptus spp., being one of the most important plantation species, has been planted in 95 countries around the world, and the area of plantation has exceeded 22.57 million ha. In the southern hemisphere, it is a significant industrial fast-growing tree species. These plantations serve as a valuable resource for the timber and fibre-based industries. Eucalyptus is the main fibre resource for the pulp and paper industries in developed countries. Timber extracted from the planted eucalyptus trees has long been used for solid wood and its fibres were used for manufacturing medium-density fibreboard. In comparison to most softwood species, Eucalyptus timber is reported to have a higher rigidity, making it ideal for manufacturing structural products. Therefore, this paper presents a review and analysis of the recent state of research on the utilisation of planted eucalyptus for engineered wood products (EWPs) manufacturing. This study investigated Eucalyptus-based EWPs such as particleboard, fibreboard, oriented strand board, laminated veneer lumber, plywood, glue laminated lumber, and cross-laminated lumber. The feasibility of using planted Eucalyptus in the production of EWPs, as well as the challenges encountered, was also discussed.

\section{Introduction}

According to the Global Forest Resources Assessment (FRA) report published by the Food and Agriculture Organization of the United Nations (FAO) in 2020, the total forests area worldwide is amounted to 4.06 billion hectares (ha), which covers $31 \%$ of the total land area [1]. Two broad categories of forests have been identified by FRA, namely, naturally regenerating forests and planted forests. Natural regenerating forests cover around 3.75 billion ha or $93 \%$ of the total forest area. Meanwhile, the total area of planted forests globally is estimated to be 294 million ha or $7 \%$ of the world forest area. Asia has the largest area of planted forests which amounted to 135.23 million ha, or $46 \%$ of the total planted forests area globally, followed by Europe, North and Central America, South America, Africa, and Oceania. Figure 1 displays the increment of the planted forest area in all regions between 1990 and 2020. As of 2020, the total planted forest area was significantly increased by $72 \%$ compared to 1990.

Planted forest typically refers to the forest that is primarily made up of trees that have been planted and/or intentionally seeding. Planted forests provide many benefits including traditional timber and fibre production, economic development, and employment in rural areas [2] and have been identified as a key means to fight climate change in the short to medium term, restore degraded land, and maintain sustainable ecosystem functions and services [3-6]. In the context of a broader geographic and economic context, wellmanaged planted forests can contribute to sustainable development [7]. Planted forests are now also being proposed as a way to reduce harvesting pressure on natural forests [8]. 


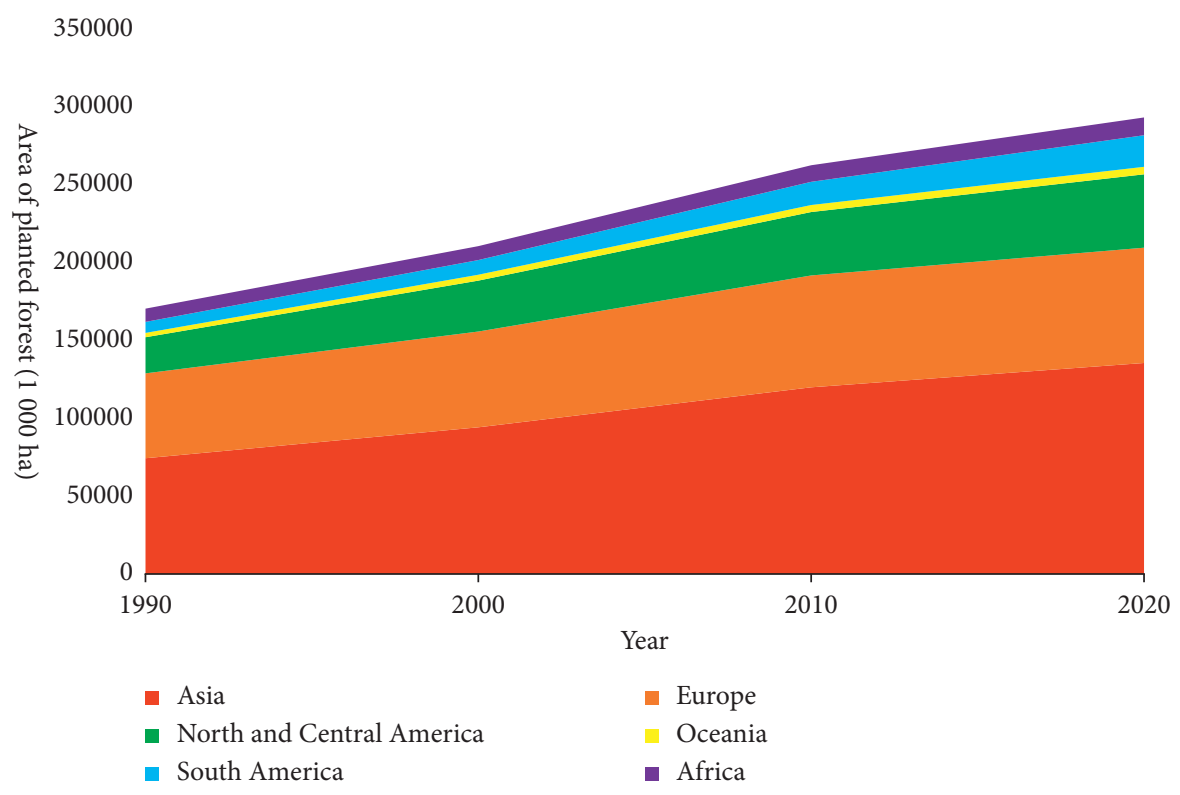

FIgURE 1: Planted forest area by region for the period 1990-2020 [1].

FRA divided the planted forests into 2 categories: plantation forests and other planted forests. Based on the definitions, plantation forests are intensively managed for productive purposes, with one or two species, even age class, and consistent spacing. Plantation forests are grown for the purpose of producing timber, fibre, energy, and nonwood forest products. A subtype of plantation forests is those primarily made up of introduced species. On the other hand, other planted forests consist of one or more tree species and are less intensively managed, typically for multiple purposes and do not meet the criteria of plantation forests and may even resemble natural forests at stand maturity. The areas of plantation forests and other planted forests by region and subregion are shown in Figure 2. Plantation forests cover 131 million ha worldwide, accounting for $45 \%$ of all planted forest land. The remaining 55\% is classified as other planted forests, which cover 163 million ha. East Asia has the highest share of plantation forests while other planted forests predominate in Europe [1].

Of all tree species being planted worldwide, Pinus species (native and nonnative) are dominant in most regions in the world, while nonnative Eucalyptus species are the most common in the tropics and subtropics [9]. Eucalyptus is typically managed on short rotation to enhance economy with the production of timber, pulpwood, charcoal, and firewood [10]. Eucalyptus is very adaptable, tolerating low soil fertility, acidic soils, and soils rich in aluminium, often periodic moisture stress, diverse climates and soil types, and even fire and insect damages and low water availability [11-15]. Other favourable characteristics of Eucalyptus include its good efficiency at capturing $\mathrm{CO}_{2}$ and producing oxygen, better efficiency in water consumption compared to other species, increasing soil fertility, and restoring land degradation or unproductive land [16, 17].According to Myburg [18] and Iglesias Trabado and Wilstermann [19], currently there are more than 100 countries across six continents around the world planting Eucalyptus and covering over 20 million ha, making it the most widely planted broad-leaved tree species worldwide. From 1990 to 2015, the global Eucalyptus plantation area increased by 16.57 million ha, with an average annual increase of 1.1 million ha. The ratio of the area of global Eucalyptus plantations to planted forests area has also increased from $3.41 \%$ to $7.80 \%$ within the same period [20]. According to Wen et al., the Eucalyptus plantation area in the top 15 countries accounts for nearly $90 \%$ of the world's total eucalyptus plantation area. Brazil (22\%) has the largest proportion of Eucalyptus plantation area in the world, followed by China (20\%), India (17\%), Australia (4\%), Uruguay (3\%), Chile (3\%), Portugal (3\%), Spain (3\%), Vietnam (3\%), South Africa (3\%), Sudan (2\%), Thailand (2\%), Peru (2\%), Argentina (1\%), and Pakistan (1\%). Although the genus Eucalyptus includes more than 700 species and their varieties, those planted for industrial purposes do not surpass a dozen. The "big nine" species (Eucalyptus camaldulensis, E. grandis, E. tereticornis, E. globulus, E. nitens, E. urophylla, E. saligna, E. dunnii, and E. pellita) and their hybrid are dominating $90 \%$ of the current Eucalyptus plantation [21]. These plantations have the potential to be easily certified with environmental certification schemes such as the Forest Stewardship Council (FSC) if the good forestry practices are followed along the productive chain.

\section{Utilization of Eucalyptus spp. Fabricating EWPs}

Eucalyptus plantations have the potential to be a valuable resource for the timber and fibre industries. However, most countries rely on Eucalyptus plantations primarily for lowvalue applications such as pulp, energy products, or board [22]. Most Eucalyptus species are rarely processed into sawn lumber due to the problems related to poor dimensional 


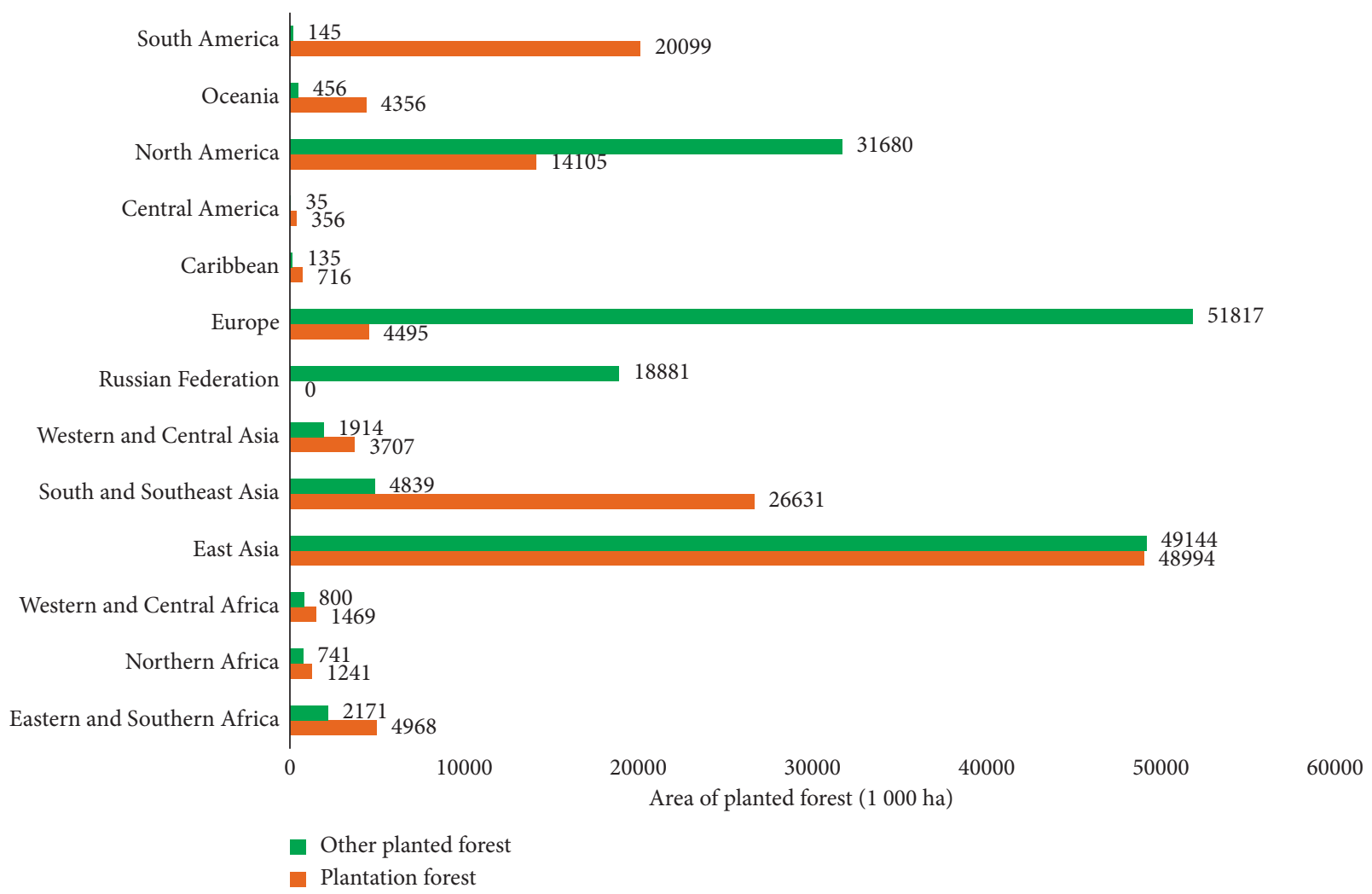

FIgURE 2: Area of plantation forest and other planted forests, by region and subregion, 2020 [1].

stability, regular knots, cell collapse, excessive radial and tangential shrinkage rate, splitting, warp, and brittle heart during processing [23-25]. Splitting, cracking, and warping is most pronounced during the drying process and can be reduced by joining the wood into engineering products or composite components before the drying process $[26,27]$. Splitting at the time of logging and warping during milling can be caused also by growth stresses [28, 29]. Growth stresses are often responsible also for brittle heart, especially in large older trees [30]. Most of these problems can be mitigated by applying the heat treatment to Eucalyptus logs [31], harvesting young eucalyptus trees, logs sawmill processing, and joining timber into EWPs before drying the wood [24, 32].

2.1. Types of EWPs. EWPs are a type of manufactured composite material made from hardwoods and softwoods. These products are frequently processed to improve their quality and capacity. EWPs comprise a wide range of product types with a variety of manufacturing processes and applications. Particleboard, plywood, fibreboard, oriented strand board (OSB), laminated veneer lumber (LVL), glue laminated timber (GLT), and cross-laminated timber (CLT) are examples of engineered wood products [33] (Figure 3).

Eucalyptus wood could be potentially converted into a wide variety of EWPs. For instance, in the production of hardboard, Eucalyptus fibres are preferred. Eucalyptus fibres are short, according to Hillis and Brown [34], and thus do not easily form little clumps or masses like lengthy fibres do.

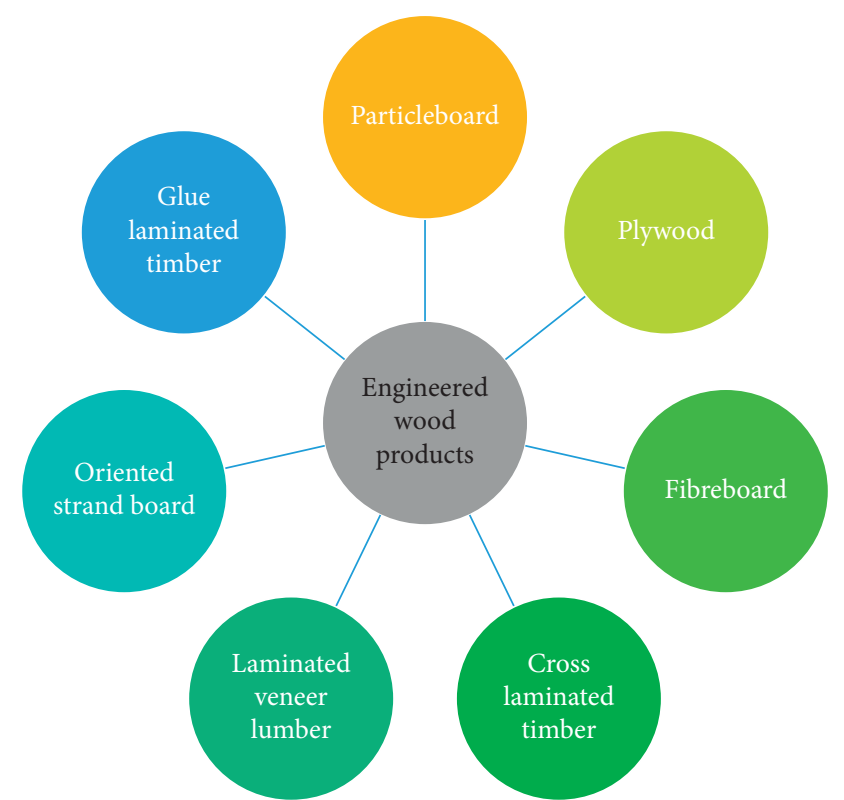

FIgURE 3: Types of engineered wood products.

As a result, the panels produced are acknowledged to have good surface attributes. Furthermore, when compared to other softwood species, Eucalyptus fibres have substantially higher strength qualities. As a result, the boards do not require any additional adhesive to provide the requisite strength. Therefore, this review would mainly focus on the studies reported Eucalyptus-based engineered wood 
products including particleboard, plywood, fibreboards, OSB, LVL, GLT, and CLT.

2.2. Publications on Eucalyptus-Based EWPs. Scopus database was used to search for the publications on EWPs fabricated from Eucalyptus spp. wood. The results are displayed in Figure 4.

The most extensively reported EWPs made from eucalyptus are particleboard, which has 127 publications in the Scopus database dating back to 1990. Researchers from Brazil were responsible for over three quarters of the articles. With a total of 100 articles, plywood is the second most widely reported product, with researchers from China and Brazil dominating the field. The production of fibreboard panels derived from eucalyptus wood was covered in 34 publications, whereas the OSB was covered in 20. Between 2012 and 2021, 25 publications on Eucalyptus-based CLT were published. Researchers from Brazil, Australia, and China dominated the published data. Between 2003 and 2021, 15 articles on glue laminated wood were found, with Brazilian researchers dominating the published data once again. The only exception is LVL, for which Australian researchers have made the biggest contributions. Since 2013, there have been a total of 18 publications on LVL made from Eucalyptus. The increasing numbers of publications over the years reveal that the application of Eucalyptus wood in the manufacturing of EWPs has become more and more important. In recent years, CLT is the most widely researched type of EWPs worldwide.

2.3. Particleboard. Several studies have demonstrated the practicality of using Eucalyptus species in particleboard manufacture. Da Rosa et al. [35] made particleboards from five eucalyptus species, i.e., Eucalyptus benthamii, E. dunni, E. grandis, E. saligna, and E. urograndis. As a control, particleboard produced from Pinus taeda was used. When compared to particleboard made from $P$. taeda, the results showed that particleboard made from Eucalyptus species had a higher modulus of rupture (MOR) and modulus of elasticity (MOE). The particleboard manufactured from E. grandis had the greatest MOR and MOE values. Particleboard manufactured from E. grandis also had the highest internal bonding (IB) strength. Overall, all of the Eucalyptus species met the minimum European EN standard requirements to the MOR and MOE values [36]. Only particleboards manufactured from $E$. grandis and E. saligna exceeded the minimum requirement of $18 \mathrm{MPa}$ for $\mathrm{MOR}$ when compared to Standard NBR14810-2 (2006) [35]. On the other hand, Rangel et al. [37] employed E. urophylla to make particleboard and found that the mechanical qualities of the boards met the German Standards Institute (DIN) and the Venezuelan Industrial Standards Commission's basic standards (COVENIN). In terms of water absorption (WA) and thickness swelling (TS), all Eucalyptus-based particleboard had greater dimensional stability than the control, as evidenced by lower WA and TS values.

Figures 5 and 6 display the MOE-density chart and MOR-density chart for particleboard made with Eucalyptus spp. and other wood species. From the figures, one can see that the bending strength of the particleboard made of different raw materials does not necessarily follow the trend of strength improved along with increasing density. The findings have been supported by Klimek and Wimmer [47]. However, it does prove that the particleboard manufactured from Eucalyptus species has comparable or even better bending strength compared to that of other wood species. Even at lower board density, particleboard made from Eucalyptus species displayed better MOE and MOR than that of particleboard made from pine, poplar, and rubber wood.

Niekerk and Pizzi (1994) reported data from studies conducted at a South African particleboard factory which utilised E. grandis as raw material and a tannin-based adhesive to produce a moisture-resistant product [48]. The authors outlined two important problems that had to be overcome, i.e., the low $\mathrm{pH}$ of the eucalypt furnish, particularly in the high steam environment in the mattress during hot pressing, which inhibited the tannin adhesive curing, and the resistance of the Eucalyptus wood particles to crushing during the hot pressing process, which resulted in poor dimensional stability of the fabricated particleboards. Cabral et al. (2007) investigated the properties of particleboards made with particles generated from planer shavings of E. grandis, E. urophylla, and E. cloeziana, bonded with urea-formaldehyde (UF) adhesive [49]. Slash pine (Pinus elliottii) particles were mixed with Eucalyptus particles to achieve a target panel density of $700 \mathrm{~kg} \cdot \mathrm{m}^{-3}$. Overall, particleboards fabricated with the highest proportions of Eucalyptus particles demonstrated the highest WA and TS values. Pan et al. (2007) studied the properties of thin particleboard panels fabricated from E. cinerea, bonded with polymeric 4,4-diphenylmethane diisocyanate (pMDI) and UF resin [39]. The properties of the panels were compared with those made from E. camaldulensis. The authors investigated a wide range of production parameters, i.e., particle size, resin type and addition level, bark content, and hot-water pretreatment. In general, particleboards produced from $E$. cinerea wood particles exhibited significantly better properties than those made from E. camaldulensis.

2.4. Fibreboard. Fibreboard is a term used to describe a flatpressed EWP manufactured from wood fibres obtained by thermomechanical wood pulping and traditionally bonded with a synthetic adhesive. In addition, hardboards represent a flat-pressed EWP composed of randomly oriented wood fibres obtained by thermomechanical wood pulping and bonded without an adhesive by hot pressing by the very high density (900-1100 kg.m ${ }^{-3}$ ) and the high-temperature-induced flow of the lignin component of the fibres [50]. Eucalyptus has been shown in several researches to be a potential material to produce fibreboard panels. Several Eucalyptus species have been reported to be used as feedstocks for medium-density fibreboard (MDF), for example, E. obliqua, E. sieberi, E. globoidea, E. loxophleba, and E. rudis [51]. Krzysik et al. [52] used E. saligna to make mediumdensity fibreboards (MDF) in three thicknesses $(6 \mathrm{~mm}$, 


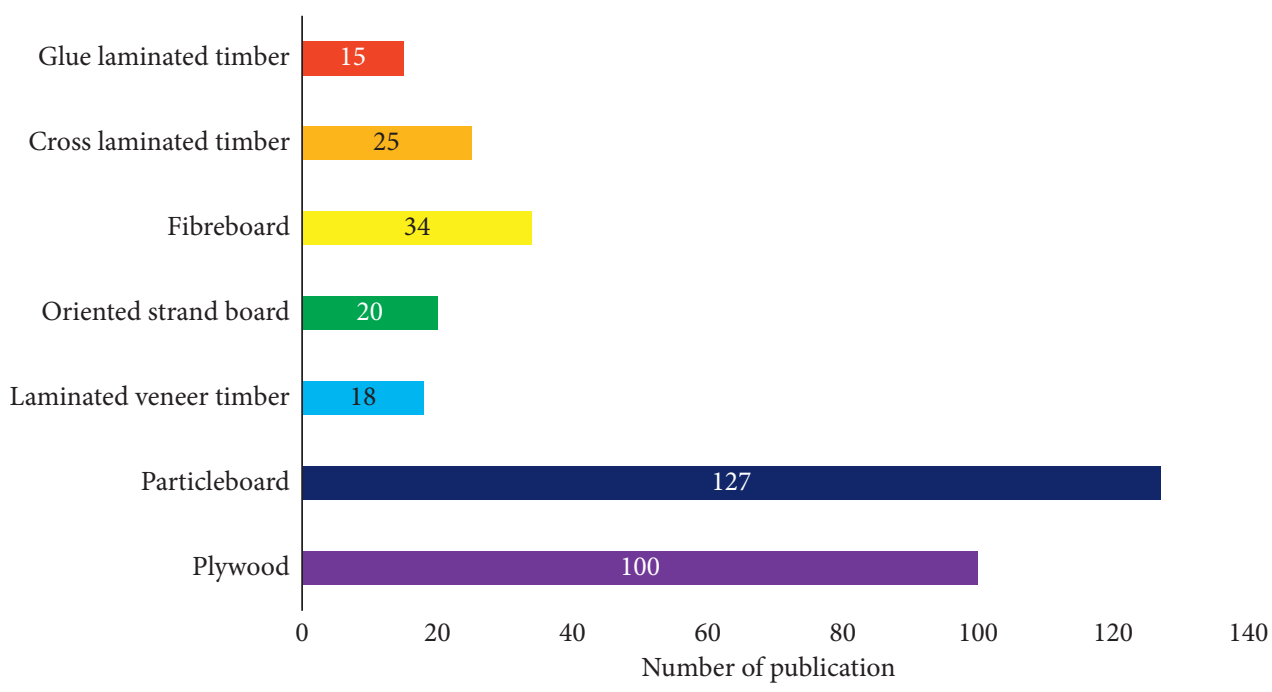

Figure 4: Number of publications on EWPs fabricated from Eucalyptus spp.

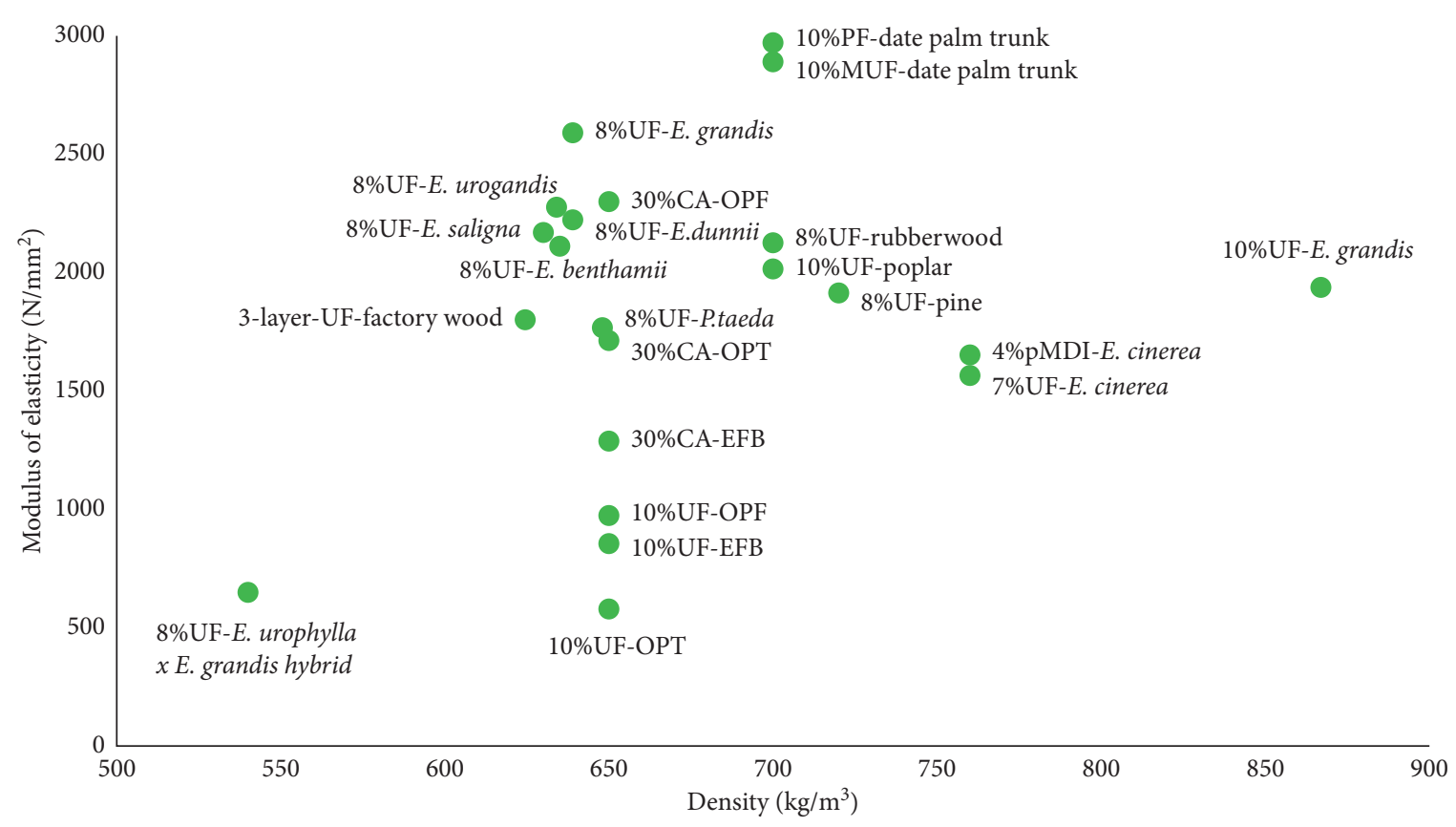

Figure 5: MOE-density chart for particleboard made with Eucalyptus spp. and other wood species [35, 38-46]. *Note: UF: ureaformaldehyde; PF: phenol-formaldehyde; MUF: melamine-urea-formaldehyde; pMDI: polymeric 4,4-diphenylmethane diisocyanate; CA: citric acid; OPT: oil palm trunk; OPF: oil palm frond; EFB: empty fruit bunch.

$13 \mathrm{~mm}$, and $19 \mathrm{~mm}$ ), bonded with $10 \% \mathrm{UF}$ resin. The produced MDF was compared to the specifications of the Interior ANSI A208.2 MDF standard [53]. The developed MDF panels exceeded the minimum MOR criteria established by the ANSI A208.2 standard for all three thicknesses examined. The laboratory-fabricated MDF panels of all three thicknesses exceeded the ANSI minimum standard requirements to MOE and IB values. Pranda [54] reported MDF panels fabricated from E. globulus and found that the resulting MDF had higher WA and TS than MDF made from Pinus pinaster. Furthermore, to achieve comparable mechanical properties, MDF panels made from E. globulus required a higher resin amount than MDF made from $P$. pinaster.

Some authors demonstrated the potential of Eucalyptus as a feedstock in manufacturing binderless fibreboards. Most of this research is based on the oxidative modification of lignin [55, 56]. Authors in [57] prepared a binderless board from Eucalyptus grandis of hydrothermal pretreated Eucalyptus wood fibres and characterized it in terms of chemical analyses, mechanical strength, and self-bonding mechanism. The reduction of lignin content of the Eucalyptus wood after hot pressing resulted in a decrease in the glass transition temperature and decrease of the softening point of lignin, 


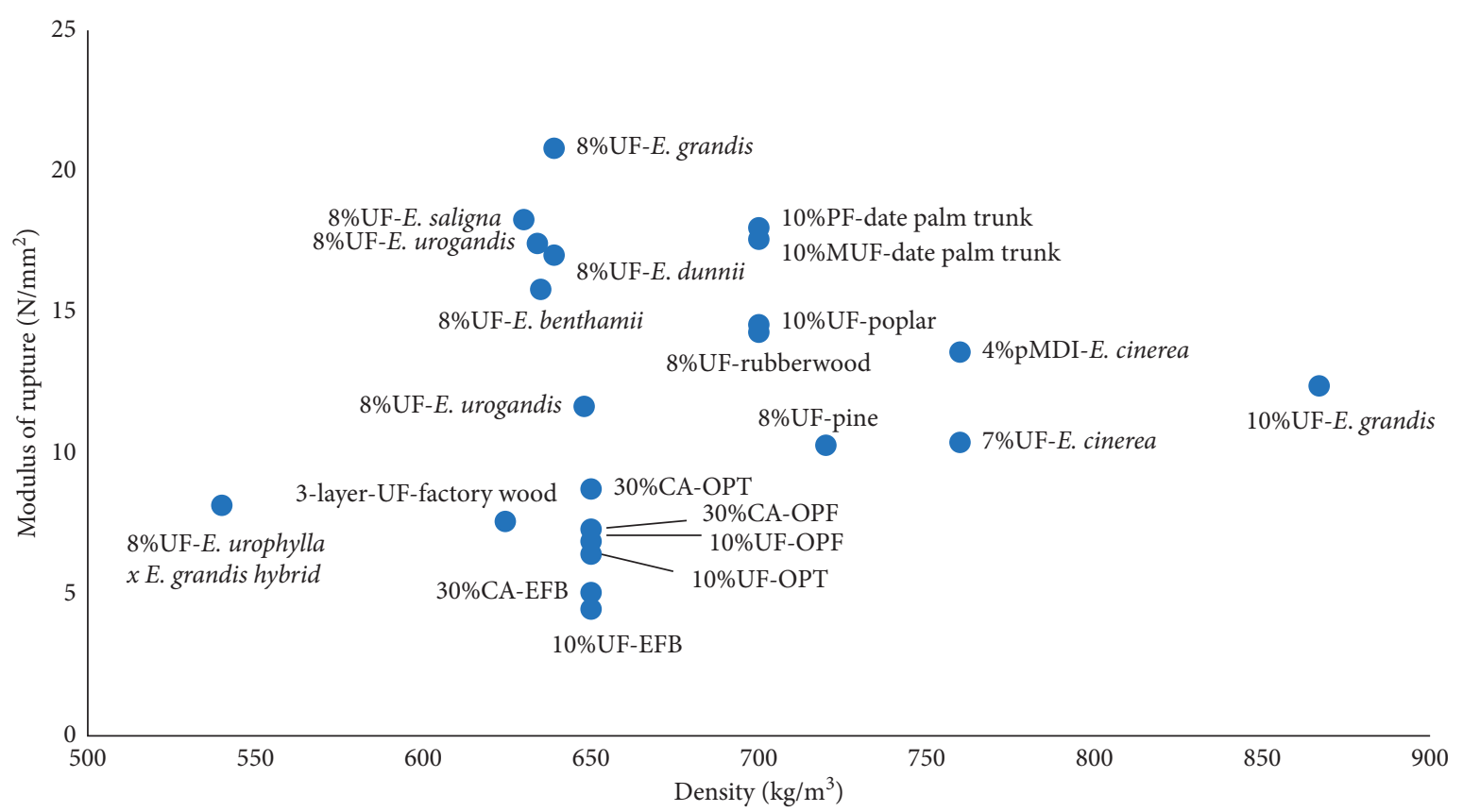

Figure 6: Modulus of rupture- (MOR-)density chart for particleboard made with Eucalyptus spp. and other wood species [35, 38-46]. ${ }^{*}$ Note: UF: urea-formaldehyde; PF: phenol-formaldehyde; MUF: melamine-urea-formaldehyde; pMDI: polymeric 4,4-diphenylmethane diisocyanate; CA: citric acid; OPT: oil palm trunk; OPF: oil palm frond; EFB: empty fruit bunch.

which makes lignin more accessible to the fibre surface and plays important role in the self-bonding mechanism $[58,59]$. It was explained that high IB value was caused by the intermolecular hydrogen bonding between the cellulose and lignin molecule [60]. In general, it was suggested that the combination of hydrothermal pretreatment and hot pressing process is a good way for conditioning Eucalyptus sawdust for the production of binderless boards [61]. Other authors in [62] used Kraft lignin (KL) from E. globulus with laccase from $M$. thermophila in a two-component system enabling the manufacturing of MDF panels totally free of synthetic resins or additives, with E. globulus as the main raw material. The MDF panels exhibited remarkable high IB and low TS values.

2.5. OSB. OSB is a type of flat-pressed EWP comparable to particleboard that is made by applying thermosetting adhesive resins to layers of wood strands and compressing them. Traditionally, wood from the Pinus genus has been used to make OSB [63]. The density of OSB made in the United States is normally between 500 and $800 \mathrm{~kg} \cdot \mathrm{m}^{-3}$. The fabrication of panel products, according to Molesmi [64], requires timber with a density of up to $550 \mathrm{~kg} \cdot \mathrm{m}^{-3}$. As a result, Eucalyptus species could be used to replace Pinus spp. wood. As a source of raw materials in the production of OSB, E. grandis has been reported as a suitable feedstock for the production of OSB panels [65]. According to the study, using 4.5 and $6 \%$ phenol-formaldehyde (MUF) resin is enough to produce OSB panels with mechanical strength complying with the Canadian Standard CSA 0437-0. A study by Domingos and Moura [66] also demonstrated that the Eucalyptus bark could be a promising material for the manufacturing of OSB panels.

Following that, several Eucalyptus species that are suited for OSB production have been found. Iwakiri et al. [67] used 6\% PF resin to make OSB from six different Eucalyptus species: E. grandis, E. dunnii, E. tereticornis, E. saligna, E. citriodora, and E. maculate. The OSB panels were produced at a density of $700 \mathrm{~kg} \cdot \mathrm{m}^{-3}$. The findings demonstrated that, in terms of physical and mechanical qualities, E. grandis and E. saligna, particularly E. grandis, had a lot of potentials for making OSB. When compared to OSB created from P. taeda, OSB made from E. grandis had equivalent or superior physical and mechanical properties. The potential of using E. grandis and E. urophylla as feedstocks in nonoriented and oriented panels was investigated by Gouveia et al. (2000) [68]. The authors concluded that E. grandis was the more suitable raw material. In addition, Gouveia et al. (2003) also investigated blends of E. grandis and Pinus elliottii feedstocks for OSB panels, and optimum results were reported with blends comprised between 50\% and 75\% E. grandis wood [69]. Another study by da Rosa et al. [35] looked at the technical feasibility of using five different Eucalyptus species to make OSB. E. benthamii, E. dunni, E. grandis, E. saligna, and E. urograndis are among the Eucalyptus species employed. When compared to OSB panels made from $P$. taeda, OSB fabricated from Eucalyptus species demonstrated higher dimensional stability. Furthermore, the MOE value of Eucalyptus OSB was higher than that of pine OSB, while there was no significant difference in MOR between the two panels. In comparison to OSB made of pine, the IB strength of OSB manufactured of Eucalyptus was shown to be lower. All five species, however, have been 
identified as suitable for the production of OSB. The practicality of OSB manufactured from E. grandis and E. dunnii was compared by Iwakiri et al. [70]. OSB was manufactured in two densities: $700 \mathrm{~kg} \cdot \mathrm{m}^{-3}$ and $1000 \mathrm{~kg} \cdot \mathrm{m}^{-3}$. OSB produced from E. grandis with a density of $700 \mathrm{~kg} . \mathrm{m}^{-3}$ met the minimum requirements set out in the Canadian and European standards. OSB panels with a higher density of $1000 \mathrm{~kg} \cdot \mathrm{m}^{-3}$ exhibited greater mechanical strength, allowing them to be used in more demanding load-bearing applications.

2.6. $L V L$. LVL is a type of EWP that is made up of numerous layers of thin wood that are adhered together. Owing to its uniform engineering properties and dimensional flexibility, LVL is a vital EWP, particularly for the construction of buildings. Several studies have proved that the LVL fabricated from Eucalyptus spp. has comparable physical and mechanical properties to that of LVL made of poplar, beech, and even Norway spruce [71, 72]. Large faults can be avoided when logs are cut into thin veneers and assembled and glued parallel to the grain, which may explain why reported LVL values are typically higher than those achieved for other traditional hardwood products [73]. Bal and Bektaş [74] stated that LVL is typically made from softwood species and low- and medium-density hardwood species with densities ranging from 290 to $693 \mathrm{~kg} \cdot \mathrm{m}^{-3}$. Several studies have found that Eucalyptus species are suitable for the generation of LVL. E. grandis was used to make LVL in a study by Bal [72], and it was compared to LVL made from poplar. The mechanical properties of $E$. grandis LVL were superior to those of poplar LVL, owing to the higher density of the E. grandis veneers. Meanwhile, E. globoidea was utilised to make LVL by Guo and Altaner [75]. Unfortunately, despite the high quality and good drying properties of the veneers acquired, the bond performance of the LVL produced is inadequate and does not fulfill The New Zealand standards. Despite some promising results that have been shown, manufacturing of LVL from Eucalyptus still encounters some problems such as glue difficulty, end-splits, and breakage of sheets of veneer [76]. Adhesive failure is one of the main issues encountered during the production of $\mathrm{Eu}$ calyptus-based LVL. However, this issue can be ameliorated by alternating lamination using poplar and Eucalyptus veneers as demonstrated by Murata et al. [77]. The authors found the alternating lamination using softer poplar veneers could reduce the quality variations of Eucalyptus and hence improved its variation in the modulus of elasticity. Apart from LVL, a new type of structural composite lumber called oriented strand lumber (OSL) has also been developed from Eucalyptus spp. Quite similar to that of LVL, OSL is fabricated using strands of wood or strips of veneer with a primary orientation along the length of the member. Chen et al. [78] manufactured oriented oblique strand lumber from Eucalyptus wood (Eucalyptus urophylla and E. grandis) and investigated their mechanical properties. The results revealed that OSL made from Eucalyptus urophylla and E. grandis had a better compressive and tensile strength in parallel-to-grain direction compared to that of the Sitka spruce, Douglas fir LVL, Spruce-pine-fir (SPF), GLT, and glue laminated bamboo. Eucalyptus-based OSL also exhibited higher flexure strength than all of the other wood and bamboo-based products in the study. The study has proven the feasibility of utilizing fast-growing Eucalyptus for general use in construction.

2.7. Plywood. The findings reported in the scientific literature on plywood panels manufactured from Eucalyptus are presented in Table 1. Most researchers were interested in the effects of species, type of adhesive, and grain direction on the mechanical properties of the plywood panels produced.

Except for the layer configuration, plywood is very similar to LVL. Plywood is made up of thin layers of wood veneer called "plies" that are bonded together with adjacent layers' wood grain rotated up to $90^{\circ}$ from one another. For the manufacturing of plywood, Iwakiri et al. [79] used the veneers of nine Eucalyptus species. E. viminalis was shown to produce the greatest overall outcomes. Meanwhile, E. phaeotricha and E. pellita veneers had lamination yields of less than $50 \%$. The shear strength of E. robusta, E. dunnii, and $E$. deanei plywood was not equal to or more than $1.0 \mathrm{MPa}$. As a result, four Eucalyptus species, namely, E. grandis, E. saligna, E. globulus, and E. viminalis were recognised as having promising potential for making exterior-use plywood.

E. pellita showed great potential in plywood manufacturing although there are some inferior properties in the veneers. The shear strength and MOR surpassed the minimum requirements. This is supported by the study conducted by Muhammad-Fitri et al. [81]. The authors investigated the effects of layers number and species arrangement on plywood made from batai (Paraserianthes falcataria), eucalyptus (E. pellita), and kelempayan (Neolamarckia cadamba). Five and seven layered plywood panels were produced with different species arrangements. For the 5-layer plywood, the arrangement was as follows: BBBBB, KBKBK, KEKEK, and KKKKK. The 7-layer plywood was a repetition of the 5-layer plywood where two more veneer layers were added using a similar sequence as of the 5-layer plywood. The results revealed that plywood made from a combination of kelempayan and Eucalyptus had significantly higher mechanical strength compared to that of plywood made from kelempayan solely especially in the perpendicular direction. The authors attributed it to the higher density of Eucalyptus veneers which provide higher strength to the plywood. Bal and Bektap [80] studied the effects of timber species regarding their density on the mechanical properties of the plywood produced. The mechanical strength values were divided by their corresponding density to minimize the effect of density. They found out that the specific MOE values of plywood fabricated from eucalyptus veneer were the highest among the other studied timber species. However, the specific MOR only showed a slightly higher value when compared to other species. The authors concluded that Eucalyptus wood provided sufficient strength to the final product and was able to enhance the performance of plywood when incorporated with other commercial timber 
TABLE 1: Studies on Eucalyptus plywood panels.

\begin{tabular}{|c|c|c|c|}
\hline Eucalyptus species & Variables & $\begin{array}{l}\text { Properties tested and } \\
\text { findings }\end{array}$ & Reference \\
\hline $\begin{array}{l}\text { Eucalyptus grandis, Eucalyptus saligna, Eucalyptus } \\
\text { globulus, Eucalyptus viminalis, Eucalyptus dunnii, } \\
\text { Eucalyptus robusta, Eucalyptus phaeotricha, Eucalyptus } \\
\text { deanei, and Eucalyptus pellita }\end{array}$ & $\begin{array}{c}\text { Species } \\
\text { parallel and perpendicular to the plane }\end{array}$ & $\begin{array}{c}\text { MOR }\left(\mathbf{N} / \mathbf{m m}^{2}\right) \\
72.23-115.68 \text { (parallel) } \\
39.46-53.43 \text { (perpendicular) } \\
\text { MOE }\left(\mathbf{N} / \mathbf{m m}^{2}\right) \\
\text { 9378-18494 (parallel) } \\
2738-4627 \text { (perpendicular) }\end{array}$ & {$[79]$} \\
\hline $\begin{array}{l}\text { Eucalyptus grandis } \\
\text { Fagus orientalis } \\
\text { Hybrid poplar (Populus } x \text { euramericana) }\end{array}$ & $\begin{array}{c}\text { Species } \\
\text { Eucalyptus grandis (A), Fagus } \\
\text { orientalis (B), and hybrid poplar (C) } \\
\text { Direction of load (parallel and } \\
\text { perpendicular) } \\
\text { Type of adhesive } \\
\text { UF, MUF, and PF }\end{array}$ & 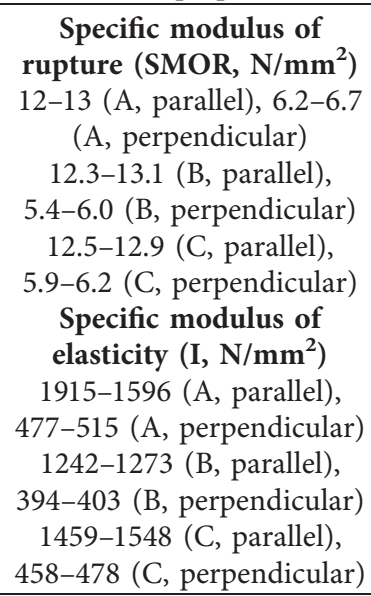 & {$[80]$} \\
\hline $\begin{array}{l}\text { Paraserianthes falcataria } \\
\text { Neolamarckia cadamba } \\
\text { Eucalyptus pellita }\end{array}$ & $\begin{array}{c}\text { Species arrangement } \\
\text { Batai (B), kelempayan-batai (KB), } \\
\text { kelempayan-Eucalyptus (KE), and } \\
\text { kelempayan }(\mathrm{K}) \\
\text { Number of layers } \\
5 \text { layers, } 7 \text { layers } \\
\text { Bending (parallel and perpendicular) }\end{array}$ & $\begin{array}{c}\text { MOR }\left(\mathbf{N} / \mathbf{m m}^{2}\right) \\
\text { 20.38-40.04 (parallel) } \\
\text { 32.39-59.82 (perpendicular) } \\
\text { MOE }\left(\mathbf{N} / \mathbf{m m}^{2}\right) \\
\text { 2453-4781 (parallel) } \\
\text { 2879-6027 (perpendicular) }\end{array}$ & {$[81]$} \\
\hline
\end{tabular}

species. The research performed by Farrell et al. (2011) was focused on assessing the potential of E. nitens and E. globulus to produce veneer and plywood. The material studied was comprised of two ages of E. nitens, i.e., 16- and 26-year-old and 33-year-old E. globulus. All plywood made from the E. globulus and the 26-year-old E. nitens veneer using phenolic adhesive achieved type A bond quality, while the results for plywood manufactured from the 16-year-old E. nitens veneer were variable [82].

2.8. GLT. GLT is a structural EWP made up of layers of dimensional lumber bound together with long-lasting, moistureresistant structural adhesives. In Europe, there is a growing interest in glued laminated structural products made of hardwoods due to a variety of factors, including a lack of softwoods. In addition, hardwoods are abundant owing to the policies of reafforestation using several hardwood species due to better adaptation to soil and climate conditions. Moreover, in most circumstances, GLT made of hardwoods has higher bending strengths than the highest European softwood GLT strength classes, which are often constructed of spruce or pine [83]. Castro and Paganini [84] used a combination of poplar and Uruguayan E. grandis to demonstrate the potential of Eucalyptus in making structural glue laminated timber. Castro and
Paganini [85] conducted a follow-up investigation in which E. grandis of four distinct clones was employed in the manufacturing of glue laminated timber. The glue laminated lumber manufactured from $E$. grandis has shown exceptional mechanical strength and structural efficiency. Apart from E. grandis, Tasmanian Oak (E. regnans/obliqua/delegatensis) and Blackbutt (E. pilularis) have also been glue laminated and their hygroscopic behaviour was examined [86]. Suleimana et al. [87] fabricated glue laminated timber from Portuguese Eucalyptus (E. globulus Labill.) and concluded that the E. globulus is suitable to be used in the production of glue laminated timber. Eucalyptus glue laminated timber is suited for structural purposes. In their investigation, Lara-Bocanegra et al. [88] found that glue laminated E. globulus timber joined with polyurethane (PUR) adhesive can reach GL45 strength class. If superior solid wood grades were employed, the GL48 strength class may be achieved. It is worth noting that if MUF resin was used to connect the glue laminated timber, strength classifications of GL56 or higher may be achieved. In comparison to the other species, the created Eucalyptus glue laminated lumber behaved flawlessly as gridshells, according to the authors. Petrauski et al. [89] employed glue laminated timber made from Eucalyptus sp. to construct porticos. The structures performed admirably and mechanically and demonstrated a high level of technical feasibility in the development of porticos. Carrasco et al. [90] used E. citriodora 
to make glue laminated timber sleepers, and the results were satisfactory, proving the viability of employing E. citriodora to make sleepers.

2.9. CLT. Table 2 summarised the findings of Eucalyptus CLT panels from various literatures. Most researchers were interested in the effects of species, type of adhesive and primer treatment, strength direction, and timber grade on the mechanical properties of the CLT panels manufactured.

A few Eucalyptus species have already been employed in the manufacturing of CLT. According to the literature, the most common resins used to bind CLT are one-component polyurethane adhesive (1C PUR) and MUF resin. Liao et al. (2017) used hybrid Eucalyptus wood (E. urophylla $\times E$. grandis) to make CLT, which they glued with a one-component polyurethane adhesive (1C PUR). They studied the pressing parameters and strength directly on the properties of CLT panels. They found out that the optimal glue spread rate, pressing pressure, and pressing time for the manufacturing of Eucalyptus CLT panels were $160 \mathrm{~g} . \mathrm{m}^{-2}$, 0.8 N.mm ${ }^{-2}$, and $200 \mathrm{~min}$, respectively. Mechanical qualities of the resulting CLT panels were comparable to commercially available CLT [96]. Other researchers also concluded that pressing pressure of $0.7 \mathrm{~N} . \mathrm{mm}^{-2}$ was sufficient to produce CLT panels with sufficient bonding quality without stress grove [94]. Nonetheless, Lu et al. [92] found that using a commercial one-component polyurethane glue led to CLT specimens with lower delamination and shear force resistance compared to commercial softwood CLT. The authors investigated the block shear strength (BSS), wood failure percentage (WFP), and delamination rate (RD) of CLT panels manufactured from hybrid Eucalyptus wood (E. urophylla $\times$ E. grandis) using different adhesives and surface primers systems. Four types of adhesives, i.e., epoxy resin (EP), emulsion polymer isocyanate (EPI), phenol resorcinol formaldehyde (PRF), and PUR, were used. Meanwhile, two surface primers, i.e., N, N-dimethylformamide (DMF) and hydroxymethylated resorcinol (HMR), were incorporated. According to the findings, all the adhesives can be utilised to make CLT. Due to its excellent bonding performance and mechanical qualities, CLT bonded with PUR adhesive demonstrated the best properties of all the studied adhesives. The authors also showed that the application of primer can further improve the BSS and WFP of the CLT specimens with HMR primer showing the highest increase in performance. However, RD of CLT showed no significant improvement with the application of surface primer treatment. Therefore, with the suitable adhesive and primer system, the shortcoming of Eucalyptus CLT can be overcome. Pangh et al. [93] employed E. nitens and E. globulus from high-grade and low-grade boards based on their MOE in the production of CLT and discovered that CLT was created from these two eucalyptus species and has better flexural qualities than CLT made from other eucalyptus species. In terms of MOE and MOR, CLT made from E. globulus outperformed E. nitens between the species evaluated. As expected, the CLT fabricated from high-grade timber board also showed better mechanical performance than their low-grade counterparts. However, the authors found out that the failure mode of the specimens was dependent on the grade of the timber board used. Bending failure on the tensile zone was common among the specimens fabricated from low-grade timber boards while rolling shear failures were observed in the specimens fabricated from high-grade timber boards. Findings from Pereira and Calil [97] also support that Eucalyptus wood is an ideal material in the production of CLT as CLT made from E. urograndis showed better properties than the CLT made from Pinus taeda. Another important aspect of the properties of CLT that needs to be taken into consideration is the rolling shear properties of the transverse layer in the CLT panel. Gui et al. [95] conducted a study to investigate the effect of aspect ratio on the rolling shear properties of CLT made from commercial SPF dimension lumber (sprucepine-fir) and E. urograndis. They concluded that the rolling shear properties of CLT panels fabricated from Eucalyptus showed promising results where the rolling shear strength and rolling shear modulus wood were $88 \%$ and $260 \%$ higher than CLT panels made from SPF lamination.

\section{Challenges and Future Perspectives}

Even though Eucalyptus spp. have shown considerable potential for manufacturing EWPs, various barriers prohibit it from being used more efficiently. The challenges could come from two factors. One factor is the current global trend of the Eucalyptus plantation. Another factor is the technical issue of the Eucalyptus wood itself. The development of plantation forests is the universal consensus and common action of global climate and ecological governance. Affected by the available forest resources, site conditions, climate change, and public opinion, the development strategies of Eucalyptus plantations in countries around the world have undergone major changes. Many countries have altered from encouraging to restricting the development of Eucalyptus plantations, making the prospects of Eucalyptus plantations uncertain (Wen et al., 2018). According to Wen et al. [20], the future development of Eucalyptus plantation is restricted by (i) unsustainable management of eucalyptus plantation under the short-cycle multigeneration continuous planting system, (ii) limited development space of Eucalyptus due to shortage of forest land resources, (iii) declining forest stand quality, and (iv) public opinion and the boycott of the development of Eucalyptus due to its excessive consumption of soil nutrients and groundwater and negative impact on biodiversity. The high number of growth stresses found in the logs is one of the key challenges. The problem was complicated by the fact that the specific chemical process responsible for the formation of such enormous stresses is still unclear [98]. Processing actions like falling, sawing, and veneer peeling resulted in the production of this growth-stressed substance. As a result, various faults occurred throughout the peeling process, including end-splitting of logs, distortion of sawn boards, and veneer cracking [25]. Worse, these flaws are more visible in plantation species with smaller log diameters. The quality and recovery of Eucalyptus veneers were ultimately harmed 
TABle 2: Studies on CLT made from Eucalyptus spp.

\begin{tabular}{|c|c|c|c|}
\hline Timber species & Variables & Properties tested and findings & Reference \\
\hline $\begin{array}{l}\text { Hybrid Eucalyptus wood } \\
\text { (Eucalyptus urophylla } \times \text { E. } \\
\text { grandis }\end{array}$ & $\begin{array}{c}\text { Pressing parameters } \\
\text { Glue spread rate (A), pressing pressure (B), and } \\
\text { pressing time (C) } \\
\text { Strength direction } \\
\text { Major strength direction (E0) and minor strength } \\
\text { direction (E90) }\end{array}$ & $\begin{array}{c}\text { Optimal pressing parameter } \\
A=160 \mathrm{~g} / \mathrm{m}^{2}, B=0.8 \mathrm{~N} / \mathrm{mm}^{2} \text {, and } C=200 \mathrm{~min} \\
\text { MOR }\left(\mathrm{N} / \mathrm{mm}^{2}\right) \\
23.8-24.5(\mathrm{E} 0) \\
8.2-9.0(\mathrm{E} 90) \\
\text { MOE }\left(\mathrm{N} / \mathrm{mm}^{2}\right) \\
11043-12034(\mathrm{E} 0) \\
661-709(\mathrm{E} 90)\end{array}$ & [91] \\
\hline
\end{tabular}

Delamination rate $(\mathrm{RD}, \%)$ $7.6-15.7$

CLT bonded with EPI adhesive displayed the highest $\mathrm{RD}$ value at $15.7 \%$. Meanwhile, PUR bonded with CLT showed the lowest RD rate at $7.6 \%$.

Adhesive

Epoxy resin (EP), emulsion polymer isocyanate

Hybrid Eucalyptus wood (Eucalyptus urophylla $\times$ E. grandis
(EPI), phenol resorcinol formaldehyde (PRF), and polyurethane (PUR) Primer

$\mathrm{N}, \mathrm{N}$-dimethylformamide (DMF) and hydroxymethylated resorcinol (HMR)
Eucalyptus nitens and Eucalyptus globulus
Species Stress grade of timber
Block shear strength (BSS, N/mm ${ }^{2}$ ) 3.01-3.51 (dry state) 1.01-1.62 (wet state)

HMR primer increased the BSS values of PRF and PUR bonded with CLT by $31.5 \%$ and $4.9 \%$, respectively.

Wood failure percentage (WFP, \%) 73.2-85.6 (dry state) 47.5-58.2 (wet state) HMR primer enhanced the WFP values of Eucalyptus CLT at wet state bonded with PRF and PUR adhesives by $27.8 \%$ and $12.4 \%$, respectively.

MOR (N/mm $\left.{ }^{2}\right)$

41.3-48.6 (E. nitens)

56.4-62.7 (E. globulus)

On average, CLT panels fabricated from

E. globulus showed $32.5 \%$ higher MOR. $\operatorname{MOE}\left(\mathrm{N} / \mathrm{mm}^{2}\right)$

9433-11695 (E. nitens)

11250-13610 (E. globulus)

On average, CLT panels fabricated from E. globulus showed $17.7 \%$ higher MOE.

Delamination values (\%)

9.7-42.8 (test A)

$14.3-58.8$ (test D)

Higher density and the presence of groove resulted in greater delamination values. In contrast, higher pressure resulted in lower delamination.

$$
\begin{gathered}
\text { Shear strength }\left(\mathrm{N} / \mathbf{m m}^{2}\right) \\
3.65-4.96 \text { (test B) } \\
5.08-6.79 \text { (test C) } \\
0.67-2.33 \text { (test D) }
\end{gathered}
$$

Higher density and pressure resulted in higher shear strength. In contrast, the presence of grooves resulted in lower shear strength.

\section{Rolling shear strength $\left(\mathrm{N} / \mathrm{mm}^{2}\right)$$$
\text { 3.46-3.65 }
$$ \\ Rolling shear modulus $\left(\mathrm{N} / \mathrm{mm}^{2}\right)$}

as a result of these flaws. Only $20 \%$ of useable veneers from E. grandis were recovered after severe end-splitting, according to Margadant [99]. Unfortunately, no technological solution to this problem has yet been discovered [75]. Apart from faults produced by growth pressures, another issue that needs to be handled is collapse and 
internal checking during the drying of eucalyptus timber. Eucalyptus lumber is difficult to dry due to its limited permeability and the presence of tyloses in the heartwood [100]. Crafford and Wessels [23] found that E. grandis has a very high shrinkage and expansion coefficient, with $30 \%$ of the E. grandis exhibiting warping that did not meet structural lumber specifications. This warping has created challenges in CLT manufacture, where good cross-grain face bonding is essential. According to Ananías et al. [101], drying flaws increased with the increased drying rates and temperatures applied. Even with very slow and cautious drying regimens, the collapse is almost unavoidable.

Despite the aforementioned concerns, various advances have been made to alleviate, if not eliminate, the obstacles associated with effective Eucalyptus timber utilisation. Wessels et al. [24] suggested some strategies for addressing the problems, including harvesting $\mathrm{Eu}$ calyptus trees at a young age, sawmill processing, and green-gluing the lumber into engineered wood products. Green gluing is the method of employing structural adhesive to join green lumber to engineered wood products before the drying process. As the adjacent pieces limit each other, drying-induced splits, cracks, and warping can be reduced. The development of structural adhesive that can be applied to green lumber above the fibre saturation point has made green glued engineered items viable. In the meanwhile, choosing the wood based on its radial placement inside the stem is critical for preventing drying-induced collapse. Wood recovered from the central region of eucalyptus lumber is less prone to collapse, according to Ananías et al. [101] than wood extracted from the transition zone between the centre and the periphery. As a result, while the negative effects of growth stresses and the drying process cannot be eradicated, they can be managed with the right processing approach.

Further research works on the potential of using $\mathrm{Eu}$ calyptus spp. for manufacturing EWPs should be focused primarily on optimising tree breeding and improving silvicultural practices, e.g., breeding for optimum density and pruning to reduce the wood defects. This would potentially result in enhanced opportunities for wider utilisation of the Eucalyptus spp. wood as a promising feedstock for manufacturing EWPs.

\section{Disclosure}

A preprint version of this manuscript is available at https:// www.researchgate.net/publication/357127148_Engineering _ Wood_Products_from_Eucalyptus_spp_A_Review [102].

\section{Conflicts of Interest}

The authors declare that they have no conflicts of interest.

\section{Acknowledgments}

This research was funded by the Transdisciplinary Fundamental Research Grant Scheme (TRGS 2018-1), reference code: TRGS/1/2018/UPM/01/2/3, by the Ministry of Higher Education (MOHE), Malaysia. This research was also supported by the Slovak Research and Development Agency under contract nos. APVV-18-0378, APVV-19-0269, and APVV-20-0159.

\section{References}

[1] Agriculture Organization of the United Nations (FAO), Global Forest Resources Assessment 2020: Main Report, FAO, Italy, 2020.

[2] A. Malkamäki, D. D’Amato, N. J. Hogarth et al., "A systematic review of the socio-economic impacts of large-scale tree plantations, worldwide," Global Environmental Change, vol. 53, pp. 90-103, 2018.

[3] J. Korhonen, P. Nepal, J. P. Prestemon, and F. W. Cubbage, "Projecting global and regional outlooks for planted forests under the shared socio-economic pathways," New Forests, vol. 52, no. 2, pp. 197-216, 2021.

[4] IPCC (Intergovernmental Panel of Climate Change), "Climate change and land summary report," 2019, https://ipcc. $\mathrm{ch} /$ report/srccl.

[5] J. Bauhus, P. J. van der Meer, and M. Kanninen, Ecosystem Goods and Services from Plantation Forests, Earthscan, United Kingdom, 2010.

[6] B. W. Griscom, J. Adams, P. W. Ellis et al., "Natural climate solutions," Proceedings of the National Academy of Sciences, vol. 114, no. 44, pp. 11645-11650, 2017.

[7] FAO, Planted Forests in Sustainable forest Management-A Statement of Principles, FAO, Italy, 2010.

[8] M. G. Betts, B. T. Phalan, C. Wolf et al., "Producing wood at least cost to biodiversity: Integrating $\mathrm{T}$ riad and sharingsparing approaches to inform forest landscape management," Biological Reviews, vol. 96, no. 4, pp. 1301-1317, 2021.

[9] C. Messier, J. Bauhus, and R. Sousa-Silva, "For the sake of resilience and multifunctionality, let's diversify planted forests," Conservation Letters, p. e12829, 2021.

[10] X. Zhou, H. Zhu, Y. Wen et al., "Effects of understory management on trade-offs and synergies between biomass carbon stock, plant diversity and timber production in eucalyptus plantations," Forest Ecology and Management, vol. 410, pp. 164-173, 2018.

[11] H. Zegeye, "Environmental and socio-economic implications of Eucalyptus in Ethiopia," in Proceeding of the Eucalyptus Species Management, History, Status and Trends in Ethiopia, pp. 184-205, Addis Ababa, September 2010.

[12] S. Zaiton, M. R. Sheriza, R. Ainishifaa, K. Alfred, and K. N. Anti, "Eucalyptus in Malaysia: Review on environmental impacts," Journal of Landscape Ecology, vol. 13, pp. 79-94, 2020.

[13] P. H. M. da Silva, F. Poggiani, P. L. Libardi, and A. N. Gonçalves, "Fertilizer management of eucalypt plantations on sandy soil in Brazil: Initial growth and nutrient cycling," For EcolManag, vol. 301, pp. 67-78, 2013. 
[14] C. Poschenrieder, B. Gunsé, I. Corrales, and J. Barceló, “A glance into aluminum toxicity and resistance in plants," The Science of the Total Environment, vol. 400, pp. 1-3, 2008.

[15] M. Ramantswana, S. P. S. Guerra, and B. T. Ersson, “Advances in the mechanization of regenerating plantation forests: A review," Current Forestry Reports, vol. 6, pp. 143-158, 2020.

[16] S. P. Grossberg, Forest Management, Nova Science Publishers, 2009.

[17] N. Sembiring, H. L. Napitupulu, A. I. Sipahutar, and M. T. Sembiring, "A review of sustainable replanting eucalyptus: Higher sustainable productivity," IOP Conference Series: Materials Science and Engineering, vol. 935, p. 012068, 2020.

[18] A. A. Myburg, "The genome of Eucalyptus grandis," Nature, vol. 510, pp. 356-362, 2014.

[19] G. Iglesias-Trabado and D. Wilstermann, "Eucalyptus Universalis. Global cultivated eucalypt forests map 2009, GIT Forestry Consulting's Eucalyptologics: Information resources on Eucalyptus cultivation worldwide," 2009, http:// www.git.forestry.com/.

[20] Y. Wen, X. Zhou, S. Yu, and H. Zhu, "The predicament and countermeasures of development of global Eucalyptus plantations," Guangxi Sciences, vol. 25, no. 2, pp. 107-116, 2018.

[21] J. A. Stanturf, E. D. Vance, T. R. Fox, and M. Kirst, "Eucalyptus beyond its native range: Environmental issues in exotic bioenergy plantations," International Journal of Forestry Research, vol. 2013, p. 463030, 2013.

[22] M. Derikvand, G. Nolan, H. Jiao, and N. Kotlarewski, "What to do with structurally low-grade wood from Australia's plantation eucalyptus; building application?" BioResources, vol. 12, no. 1, pp. 4-7, 2017.

[23] P. L. Crafford and C. B. Wessels, "A potential new product for roof truss manufacturing: Young, green finger-jointed Eucalyptus grandislumber," Southern Forests: A Journal of Forest Science, vol. 78, no. 1, pp. 61-71, 2016.

[24] C. B. Wessels, M. Nocetti, M. Brunetti et al., "Green-glued engineered products from fast growing Eucalyptus trees: A review," European Journal of Wood and Wood Products, vol. 78, no. 5, pp. 933-940, 2020.

[25] J. L. Yang and G. Waugh, "Growth stress, its measurement and effects," Australian Forestry, vol. 64, pp. 127-135, 2001.

[26] M. Pröller, M. Nocetti, M. Brunetti, M.-C. Barbu, M. Blumentritt, and C. B. Wessels, "Influence of processing parameters and wood properties on the edge gluing of green Eucalyptus grandis with a onecomponent PUR adhesive," Eur J Wood Prod, vol. 76, pp. 1195-1204, 2018.

[27] C. Pagel, Investigation into Material Resistance Factors and Properties of Young, Engineered Eucalyptus Grandis Timber, , Thesis, Department of Civil Engineering, Stellenbosch University, 2018.

[28] M. Kojima, T. Nakai, K. Saegusa, F. M. Yamaji, H. Yamamoto, and S. Yamashita, "Anatomical and chemical factors affecting tensile growth stress in Eucalyptus grandis plantations at different latitudes in Brazil," Canadian Journal of Research, vol. 42, no. 1, p. 134, 2012.

[29] R. Washusen, J. Ilic, and G. Waugh, "The relationship between longitudinal growth strain and the occurrence of gelatinous fibers in 10-and 11-year-old Eucalyptus globulus Labill," HolzRohWerkst, vol. 61, no. 4, pp. 299-303, 2003.

[30] F. S. Malan, "The wood quality of the South African timber resource for high-value solid wood products and its role in sustainable forestry," South AfrFor J, vol. 198, pp. 53-62, 2003.

[31] C. Rozas, M. Vasquez, P. T. Vega, A. Sinha, and C. Montero, "Effect of log heat treatment on release of growth stresses in Eucalyptus Nitens," Wood and Fiber Science, vol. 53, no. 3, pp. 178-193, 2021.

[32] B. C. Bal and I. Bektaş, "The effects of wood species, load direction, and adhesives on bending properties of laminated veneer lumber," BioResources, vol. 7, no. 3, pp. 3104-3112, 2012.

[33] New Nordic Timber, "Engineered wood products," 2019, https://newnordictimber.com/articles/engineered-woodproducts.

[34] W. E. Hillis and A. G. Brown, "Eucalyptus for wood production. Chapter 14," in Reconstituted Wood Products, pp. 317-321, Common-wealth Scientific and Industrial Research Organization (CSIRO), Melbourne, Victoria, Australia, 1978.

[35] T. S. Da Rosa, R. Trianoski, S. Iwakiri, and G. M. Bonduelle, "Use of five eucalyptus species for particleboards manufacture," Revista Árvore, vol. 41, no. 2, p. e410215, 2017.

[36] European Committee for Standardization, Wood-Based Panels - Determination Of Modulus Of Elasticity In Bending And of Bending Strength; EN 310, European Committee for Standardization, Brussels, Belgium, 1999.

[37] L. Rangel, P. Moreno, S. Trejo, and S. Valero, "Properties particleboards manufactured with Eucalyptus urophylla wood," Maderas: Ciencia y Tecnología, vol. 19, no. 3, 2017.

[38] M. V. Scatolino, A. D. O. Costa, J. B. Guimarães, T. D. P. Protásio, R. F. Mendes, and L. M. Mendes, "Eucalyptus wood and coffee parchment for particleboard production: Physical and mechanical properties," Ciencia E Agrotecnologia, vol. 41, pp. 139-146, 2017.

[39] Z. Pan, Y. Zheng, R. Zhang, and B. M. Jenkins, "Physical properties of thin particleboard made from saline eucalyptus," Industrial Crops and Products, vol. 26, no. 2, pp. 185-194, 2007.

[40] R. Zakaria, P. Bawon, S. H. Lee et al., "Properties of particleboard from oil palm biomasses bonded with citric acid and tapioca starch," Polymers, vol. 13, no. 20, p. 3494, 2021.

[41] S. H. Lee, W. C. Lum, A. Zaidon, and M. Maminski, "Microstructural, mechanical and physical properties of post heat-treated melamine-fortified urea formaldehyde-bonded particleboard," European Journal of Wood and Wood Products, vol. 73, no. 5, pp. 607-616, 2015.

[42] P. Bekhta, G. Noshchenko, R. Réh et al., "Properties of ecofriendly particleboards bonded with lignosulfonate-ureaformaldehyde adhesives and pMDI as a crosslinker," $\mathrm{Ma}$ terials, vol. 14, no. 17, p. 4875, 2021.

[43] A. Valle, B. S. Ferreira, G. A. Prates, D. Goveia, and C. I. D. Campos, "Physical and mechanical properties of particleboard from Eucalyptus grandis produced by urea formaldehyde resin with $\mathrm{SiO} 2$ nanoparticles," Engenharia Agrícola, vol. 40, pp. 289-293, 2020.

[44] A. Jahan-Latibari and M. Roohnia, "Potential of utilization of the residues from poplar plantation for particleboard production in Iran," Journal of Forestry Research, vol. 21, no. 4, pp. 503-508, 2010.

[45] S. Iwakiri, R. Trianoski, D. Chies et al., "Use of residues of forestry exploration of Pinus taeda for particleboard manufacture," Revista Árvore, vol. 41, no. 3, p. e410304, 2017.

[46] S. Amirou, A. Zerizer, A. Pizzi, I. Haddadou, and X. Zhou, "Particleboards production from date palm biomass," Eur. J. Wood Wood Prod, vol. 71, no. 6, pp. 717-723, 2013. 
[47] P. Klimek and R. Wimmer, "Alternative raw materials for bio-based composites," ProLingo, vol. 13, no. 4, pp. 27-41, 2017.

[48] I. A. Niekerk and A. van \&Pizzi, "Characteristic industrial technology for exterior Eucalyptus particleboard," Holz als Roh- und Werkstoff, vol. 52, pp. 109-112, 1994.

[49] C. P. Cabral, B. R. Vital, R. M. D. Lucia, and A. S. Pimenta, "Properties of particleboards manufactured with mixed particles from Eucalyptus spp. and Pinus elliottii," Revista Árvore, vol. 31, no. 5, pp. 897-905, 2007.

[50] A. Pizzi, A. N. Papadopoulos, and F. Policardi, "Wood composites and their polymer binders," Polymers, vol. 12, p. $1115,2020$.

[51] G. Freischmidt and P. Blakemore, "Potential applications of the native hardwood resource available to VicForests as wood composite products," CSIRO Materials Science \& Engineering, Client Report No. CMSE(C)-2008-312, 2009.

[52] A. M. Krzysik, J. H. Muehl, J. A. Youngquist, and F. S. Franca, "Medium density fiberboard made from Eucalyptus saligna," Forest Products Journal, vol. 51, no. 10, pp. 47-50, 2001.

[53] American National Standards, ANSI A208.2-2002. Medium Density Fiberboard (MDF) for interior Applications, Gaithersburg, MD, USA, 2002.

[54] J. Pranda, "Medium density fiber-boards made from Pinus pinaster and Eucalyptus globulus wood. Part I. Chemical composition and specific surface area of defibrated wood," Drevarsky Vyskum, vol. 40, no. 2, pp. 19-28, 1995.

[55] C. Álvarez, B. Rojano, O. Almaza, O. J. Rojas, and P. Gañán, "Self-bonding boards from plantain fiber bundles after enzymatic treatment: Adhesion improvement of lignocellulosic products by enzymatic pre-treatment," Journal of Polymers and the Environment, vol. 19, pp. 182-188, 2011.

[56] P. Widsten and A. Kandelbauer, "Adhesion improvement of lignocellulosic products by enzymatic pre-treatment," Biotechnology Advances, vol. 26, pp. 379-386, 2008.

[57] L.-P. Xiao, Z. Lin, W.-X. Peng et al., "Sustain," Chemical Processing, vol. 2, no. 1, p. 9, 2014.

[58] M. N. Anglès, F. Ferrando, X. Farriol, and J. Salvadó, "Suitability of steam exploded residual softwood for the production of binderless panels: Effect of the pre-treatment severity and lignin addition," Biomass and Bioenergy, vol. 21, pp. 211-224, 2001.

[59] W. Hsu, W. Schwald, M. J. Schwald, and M. J. Shields, "Chemical and physical changes required for producing dimensionally stable wood-based composites," Wood Science and Technology, vol. 22, pp. 281-289, 1988.

[60] W. N. A. W. Nadhari, R. Hashim, O. Sulaiman, M. Sato, T. Sugimoto, and M. E. Selamat, "Utilization of oil palm trunk waste for manufacturing of binderless particleboard: Optimization study," BioResources, vol. 8, pp. 1675-1696, 2013.

[61] M. Nasir, D. P. Khali, M. Jawaid et al., "Recent development in binderless fiberboard fabrication from agricultural residues: A review," Construction and Building Materials, vol. 211, pp. 502-516, 2019.

[62] S. Gouveia, L. A. Otero, C. F. Costas, D. Filgueira, A. Sanroman, and D. Moldes, "Green binder based on enzymatically polymerized eucalypt Kraft lignin for fiberboard manufacturing: A preliminary study," Polymers, vol. 10, p. 642,2018

[63] R. D. A. Delucis, P. S. B. D. Santos, R. Beltrame, and D. A. Gatto, "Chemical and fuel properties of forestry wastes from pine plantations," Revista Árvore, vol. 41, no. 5, p. e410507, 2017.

[64] A. A. Moslemi, Particleboard, Southern Illinóis University Press, Carbandale, 1974.

[65] S. Iwakiri, L. M. Mendes, and L. K. Saldanha, "Production of Oriented Strand Board (OSB) from Eucalyptus Grandis with different resin content, wax sizing and face to core layer ratios," Ciência Florestal, vol. 13, no. 1, pp. 89-94, 2003.

[66] B. Domingos and J. Moura, "Viabilty of eucalyptus bark for the composition of OSB panels," BioRes, vol. 14, no. 4, pp. 9472-9484, 2019.

[67] S. Iwakiri, L. M. Mendes, L. K. Saldanha, and J. C. Santos, "Utilização da madeira de eucaliptonaprodução de chapas de partículasorientadas - OSB," Cerne, vol. 10, no. 1, pp. 46-52, 2004.

[68] F. N. Gouveia, M. A. E. Santana, and M. R. Souza, "The use of Eucalyptus grandis W. Hill ex Maiden and Eucalyptus urophylla S.T. Blake for the production of non-oriented and oriented strand board," Revista Árvore, vol. 24, no. 1, pp. 7-12, 2000.

[69] F. N. Gouveia, B. R. Vital, and M. A. E. Santana, "Oriented strand boards production from a mixture of Eucalyptus grandis W. Hill ex Maiden and Pinus elliottiiEngelm," BrasilFlorestal, vol. 22, no. 77, pp. 21-27, 2003.

[70] S. Iwakiri, C. E. C. de Albuquerque, J. G. Prata, and A. C. B. Costa, "Utilization of wood of Eucalyptus grandis and Eucalyptus dunniifor oriented strand board-OSB manufacturing," Ciência Florestal, vol. 18, no. 2, pp. 265-270, 2008.

[71] I. Aydın, S. Çolak, G. Çolakoğlu, and E. Salih, "A comparative study on some physical and mechanical properties of laminated veneer lumber (LVL) produced from Beech (Fagus orientalis Lipsky) and Eucalyptus (Eucalyptus camaldulensisDehn.) veneers," Holz Als Roh-Und Werkstoff, vol. 62, no. 3, pp. 218-220, 2004.

[72] B. C. Bal, "Some technological properties of laminated veneer lumber produced with fast-growing Poplar and Eucalyptus," Maderas: Ciencia Y Tecnología, vol. 18, no. 3, pp. 413-424, 2016.

[73] J. Saviana, S. Zitto, and J. C. Piter, "Bending strength and stiffness of structural laminated veneer lumber manufactured from fast-growing Argentinean Eucalyptus grandis," Maderas. CienciayTecnología, vol. 11, no. 3, pp. 183-190, 2009.

[74] B. C. Bal and I. Bektaş, "The effects of some factors on the impact bending strength of laminated veneer lumber," BioResources, vol. 7, no. 4, pp. 5855-5863, 2012 b.

[75] F. Guo and C. M. Altaner, "Properties of rotary peeled veneer and laminated veneer lumber (LVL) from New Zealand grown Eucalyptus globoidea," New Zealand Journal of Forestry Science, vol. 48, no. 1, p. 3, 2018.

[76] D. Gaunt, B. Penellum, and H. M. McKenzie, "Eucalyptus nitens laminated veneer lumber structural properties," New Zealand Journal of Forestry Science, vol. 3, no. 1, pp. 114-125, 2003.

[77] K. Murata, M. Nakano, K. Miyazaki et al., "Utilization of Chinese fast-growing trees and the effect of alternating lamination using mixed-species eucalyptus and poplar veneers," Journal of Wood Science, vol. 67, no. 1, p. 5, 2021.

[78] J. Chen, H. Xiong, Z. Wang, and L. Yang, "Mechanical properties of a eucalyptus-based oriented oblique strand lumber for structural applications," Journal of Renewable Materials, vol. 7, no. 11, pp. 1147-1164, 2019.

[79] S. Iwakiri, J. L. M. de Matos, J. G. Prata, R. Trianoski, and L. S. da Silva, "Evaluation of the use potential of nine species 
of genus Eucalyptus for production of veneers and plywood panels," Cerne, vol. 19, no. 2, pp. 263-269, 2013.

[80] B. C. Bal and Ý. Bektap, "Some mechanical properties of plywood produced from eucalyptus, beech, and poplar veneer," Maderas: Ciencia y Tecnología, vol. 16, no. 1, pp. 99-108, 2014.

[81] S. Muhammad-Fitri, M. Suffian, W. A. R. Wan-Mohd-Nazri, and Y. Nor-Yuziah, "Mechanical properties of plywood from batai (Paraserianthesfalcataria), eucalyptus (Eucalyptus pellita) and kelempayan (NeolamarckiaCadamba) with different layer and species arrangement," Journal of Tropical Forest Science, vol. 30, no. 1, pp. 58-66, 2018.

[82] R. Farrell, S. Blum, D. Williams, and D. Blackburn, The Potential to Recover Higher Value Veneer Products from Fibre Managed Plantation Eucalypts and Broaden Market Opportunities for This Resource: Part A, Forest and Wood Products Australia Ltd, Melbourne VIC, Australia, 2011.

[83] S. Aicher, Z. Christian, and G. Dill-Langer, "Hardwood glulams-emerging timber products of superior mechanical properties," in Proceedings of the World Conference on Timber Engineering, Quebec City, QC, Canada, August 2014.

[84] G. Castro and F. Paganini, "Poplar-Eucalyptus glued laminated timber," in Proceeding of the Industrial End-uses of Fast-grown Species: Eurowood Technical Workshop Proceedings, pp. 147-166, Florence, June 1999.

[85] G. Castro and F. Paganini, "Mixed glued laminated timber of poplar and Eucalyptus grandis clones," HolzalsRoh-und Werkstoff, vol. 61, no. 4, pp. 291-298, 2003.

[86] A. A. Chiniforush, A. Akbarnezhad, H. Valipour, and S. Malekmohammadi, "Moisture and temperature induced swelling/shrinkage of softwood and hardwood glulam and LVL: An experimental study," Construction and Building Materials, vol. 207, pp. 70-83, 2019.

[87] A. Suleimana, C. S. Sena, J. M. Branco, and A. Camões, "Ability to glue Portuguese eucalyptus elements," Buildings, vol. 10, no. 7, p. 133, 2020.

[88] A. J. Lara-Bocanegra, A. Majano-Majano, F. Arriaga, and M. Guaita, "Eucalyptus globulus finger jointed solid timber and glued laminated timber with superior mechanical properties: Characterisation and application in strained gridshells," Construction and Building Materials, vol. 265, no. 2020, p. 120355, 2020.

[89] S. M. F. C. Petrauski, J. C. Silva, A. Petrauski, and R. M. D. Lucia, "Analysis of eucalyptus glued-laminated timber porticos structural performance," Revista Árvore, vol. 40, no. 5, pp. 931-939, 2016.

[90] E. V. M. Carrasco, L. B. Passos, and J. N. R. Mantilla, "Structural behavior evaluation of Brazilian glulam wood sleepers when submitted to static load," Construction and Building Materials, vol. 26, no. 1, pp. 334-343, 2012.

[91] Y. Liao, D. Tu, J. Zhou et al., "Feasibility of manufacturing cross-laminated timber using fast-grown small diameter eucalyptus lumbers," Construction and Building Materials, vol. 132, pp. 508-515, 2017.

[92] Z. Lu, H. Zhou, Y. Liao, and C. Hu, "Effects of surface treatment and adhesives on bond performance and mechanical properties of cross-laminated timber (CLT) made from small diameter Eucalyptus timber," Construction and Building Materials, vol. 161, no. 2018, pp. 9-15, 2018.

[93] H. Pangh, H. Z. Hosseinabadi, N. Kotlarewski, P. Moradpour, M. Lee, and G. Nolan, "Flexural performance of cross-laminated timber constructed from fibre-managed plantation eucalyptus," Construction and Building Materials, vol. 208, pp. 535-542, 2019.
[94] M. Dugmore, M. Nocetti, M. Brunetti, Z. Naghizadeh, and C. B. Wessels, "Bonding quality of cross-laminated timber: Evaluation of test methods on Eucalyptus grandis panels," Construction and Building Materials, vol. 211, pp. 217-227, 2019.

[95] T. Gui, S. Cai, Z. Wang, and J. Zhou, "Influence of aspect ratio on rolling shear properties of fast-grown small diameter eucalyptus lumber," Journal of Renewable Materials, vol. 8, no. 9, pp. 1053-1066, 2020.

[96] J. Zhou, Y. H. Chui, M. Gong, and L. Hu, "Simultaneous measurement of elastic constants of full-size engineered wood-based panels by modal testing," Holzforschung, vol. 70, no. 7, pp. 673-682, 2016.

[97] M. C. M. Pereira, M. C. de Moraes, and C. Calil, "Strength and stiffness of cross laminated timber (CLT) panels produced with Pinus and Eucalyptus: Experimental and analytical comparisons," Matèria. Revista Internacional d'Art, vol. 24, no. 2, 2019.

[98] T. Alméras and B. Clair, "Critical review on the mechanisms of maturation stress generation in trees," Journal of The Royal Society Interface, vol. 13, no. 122, p. 20160550, 2016.

[99] R. Margadant, "Why not peel locally grown eucalyptus," Wood Southern Africa, vol. 6, no. 10, pp. 8-22, 1981.

[100] L. R. Zen, T. C. Monteiro, W. Schaeffer, J. M. Kaminski, and R. J. Klitzke, "Secagemaoar livre da madeira serrada de eucalipto," Journal of Biotechnology and Biodiversity, vol. 7, no. 2, pp. 291-298, 2019.

[101] R. A. Ananías, V. Sepúlveda-Villarroel, N. Pérez-Peña et al., "Collapse of Eucalyptus nitens wood after drying depending on the radial location within the stem," Drying Technology, vol. 32, no. 14, pp. 1699-1705, 2014.

[102] S. H. Lee, W. C. Lum, P. Antov, L. Kristak, and M. T. Paridah, "Engineering wood products from Eucalyptus spp," 2021, https://www.researchgate.net/publication/357127148_Engin eering_Wood_Products_from_Eucalyptus_spp_A_Review. 